\title{
A Study on Relationship Between Carrying Schoolbags and The Prevalence of Neck and Back Pain Among 7 - 9 Year Old Students
}

\author{
N. Kabilmiharbi ${ }^{1}$ and T. Santhirasegaram ${ }^{1}$ \\ ${ }^{1}$ Mechanical Engineering Department, Universiti Tenaga Nasional (UNITEN), Malaysia
}

\begin{abstract}
There is a growing concern these days that children are carrying way too much weight on their backs. School students are at risk of developing Musculoskeletal Disorder or possibly long term back pain due to the frequent exposure of carrying heavy schoolbags. In Malaysia, this problem is currently an overlooked issue as not many are aware of the importance of maximum allowable load that should be carried by school students together with proper posture and how all these will affect the children in the future. An interview was conducted based on 90 school students of age 7 to 9 year old regarding the body part discomfort that they experience while carrying the schoolbag. Furthermore, the weight of the schoolbag and the student's height and weight was taken for this study. The responses were classified based on age and gender as the anthropometry differs on ages and gender. A statistical analysis is carried out with the results obtained. The finding of the statistical analysis showed that the prevalence of neck and back pain does exist among 7-9 year old school students and almost 90 of them are affected. Among the main problems are that the schoolbag design, the incorrect ways of carrying the schoolbag, the excessive weight of the schoolbag and the prolonged duration of constantly carrying the schoolbag. Necessary action should be taken to overcome these problems.
\end{abstract}

\section{Introduction}

School students usually caries their schoolbag to, from and around the school which inside the schoolbag contains their textbooks, sports attire, packed meals and stationaries. There has been a growing concern around the world these days regarding the school children that carrys way too much weight on their backs. Some countries are coming up with variety of ways on how to overcome this issue such as electronic based learning where students are provided with tablets or laptops and they only need to carry the laptops or tablets to school instead of the heavy school books or by making their study materials available online which will then reduce the burden of carrying heavy textbooks to school. Contrary, in Malaysia, the risk factors of carrying heavy schoolbag faced by school students are currently an overlooked issue as Malaysians are not well exposed on the ergonomics awareness where there are merely few studies and reports done in Malaysia regarding this issue $[1,2,3]$.

According to Dutch Labour Inspectorate, to prevent work-related back disorders as a result of lifting, the maximum load mass to be lifted by one adult worker is to be $25 \mathrm{~kg}$ and if it is more than that, it should be lifted by more than one workers provided it is not more than 50 $\mathrm{kg}$ and loads which are more than $50 \mathrm{~kg}$ should always be lifted mechanically [4]. Furthermore, according to the National Institute of Occupational Safety and Health, there are different weight limit among different countries and the mean carrying weight for boys and girls not more than 16 years old of age are $14 \mathrm{~kg}$ and $8 \mathrm{~kg}$ [5]. Meanwhile, for primary school students, $10 \%$ of body weight (BW) has been commonly accepted as a recommended schoolbag weight as the physical capability of school children are different from the adults [6]. The National Back Pain Association recorded that the schoolbag weights for British children of 13 -year olds is $10.4 \%$ of their body weight and $10.2 \%$ of their body weight for 16 year old children [7]. Besides that, an investigation was done to see the effect of backpacks where athletic bags were loaded with $17 \%$ of student's body weight and a conclusion was made that the carriage of schoolbags significantly altered the posture and gait of students and the result may leads to a variety of musculoskeletal complaints such as muscle soreness, back pain, numbness and shoulder pain [8]. Furthermore, the National Back Pain Association has created a guideline which suggested that in an ideal world, a schoolbag should weigh under $10 \%$ of the student's body weight and this weight should be held on both shoulders in a backpack style schoolbag [5]. All these research proves that school children carrying heavy school bags are subjected to MSDs in the long run. 
School students are at risk of developing Musculoskeletal Disorder or possibly long term back pain due to the frequent exposure of carrying heavy schoolbags. A research done on the weight of schoolbags and prevalence of musculoskeletal symptoms amongst 140 students in New Zealand found that the students were carrying weights which exceeds the recommended guideline load limits for an adult industrial workers and carrying heavy schoolbags was suspected as the contributory [6]. The research shows that $77.1 \%$ of the students reported to suffer from musculoskeletal symptoms and the symptoms was most prevalent in the neck, shoulders, upper back and lower back. Furthermore, another recent study in Ireland also found that the prevalence of baseline musculoskeletal discomfort was as high as $63.4 \%$ on student of mean age 10.6 , where schoolbag related discomfort was reported more frequently on the shoulders $(27.3 \%)$ than on the back $(15 \%)$ and time factor was also taken into account as most students carried their bags for almost less than 10 minutes [9]. This shows that students who carries heavy burden on their back more than the recommended weight will somehow develop pain on their neck shoulders and back which might leads to Musculoskeletal disorder at early age.

School students are responsible on carrying their own schoolbag and so it is important for each students to carry their schoolbag properly in order to avoid or minimize postural problems, back pain and musculoskeletal disorder. There are proper ways on carrying a load and this is also applied on carrying a luggage or a bag. Carrying a load in a lateral position, such as carrying a suitcase by hand, requires a greater muscular effort in the contralateral muscles compared to carriage in a backpack where it requires less muscular effort in the lower back [10]. Besides that, carrying a backpack was associated with a lower heart rate and oxygen uptake than with shoulder load carriage where carrying materials on the back seems to be an acceptable method of load carriage as long as it follows the safety guidelines in carrying which are the load should be kept as close as possible to the trunk and heavy load should not be carried using small muscle groups, and optimum use should be made of large muscle groups of the body in order to minimize fatigue and local muscle discomfort [11].

Hence, the objective of this study is to investigate the relationship between carrying schoolbag and the prevalence of neck and back pain among students aged 7 to 9 years old by interviewing the students on their discomfort level experienced while carrying the schoolbag. It is important to study on how carrying schoolbag affected the students and the risk factors which causes the occurrence of neck and back pain among them. Furthermore, the results can be used to help promoting the ergonomics awareness among the parents, teachers, educational institutions, medical professionals and the government.

\section{Methodology}

\subsection{Focus of the Study}

This study was conducted on 90 school students aged 7 to 9 years old at a primary school in Shah Alam, Selangor. There are a total of 43 male students and 47 female students and 30 students were taken for each age, 7, 8 and 9 years old. All the students were interviewed and the height and weight of each student were taken followed by measuring the weight of their respective schoolbags.

\subsection{Observation on the students}

An interview was done to all the students by modifying the Nordic questionnaire in order to gather information regarding the occurrence discomfort experienced by the students. The modified Nordic questionnaire is used together with a Visual Analogue Scale (VAS) as shown in Figure 1. This is to help the students provide a more accurate responses to the intended questions and the usage of VAS with a questionnaire is very common in research conducted among school children as it would be much easier for kids to understand since it is more graphical rather than words $[6,8,10,11]$. Furthermore, the height and weight of the students were measured together with the weight of their respective schoolbags.

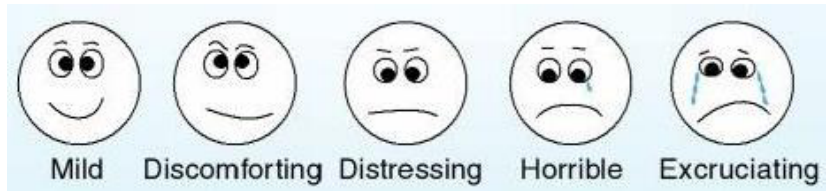

Figure 1. The Visual Analogue Scale (VAS) used to interview the students.

\subsection{Analysis}

After observation and data collection, the method used to analyze the data is the same as done in previous studies $[6,13]$ where the mean weight and height of each group of students by age and gender are being evaluated. This is then compared with the mean weight of this schoolbags to obtain the percentage of weight of their schoolbag to their body weight. The method is used as it is recommended that school children are only allowed to carry load which is $10 \%$ of their body weight. Necessary action and suggestion will be discussed based on the results obtain form the analysis done.

\section{Results and Discussion}

\subsection{Respondent Profile}

The response rate for this survey varied by age and gender group from $14.44 \%$ to $18.89 \%$. The highest number of responses were from 9 year old female students (17 respondents) and the lowest were from 9 year old male students (13 respondents) as shown in Figure 2 below. 


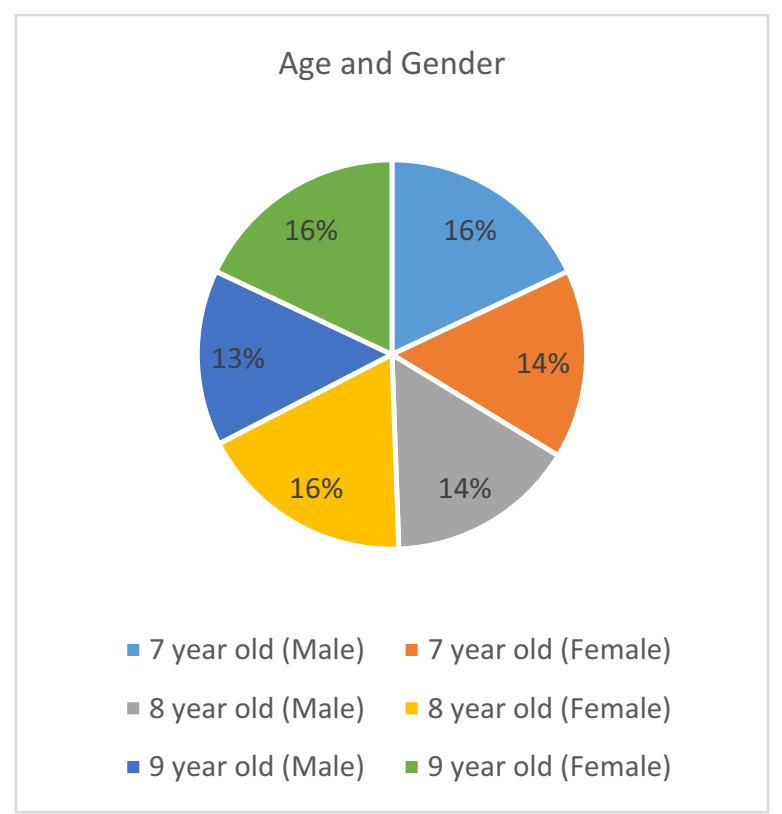

Figure 2. Age and gender of the respondents.

\subsection{Statistical Analysis}

\subsubsection{7 year old male student}

There are 16 respondents from this group where the range of weight are from $22.1 \mathrm{~kg}$ to $32.4 \mathrm{~kg}$ and the range of height were from $118 \mathrm{~cm}$ to $132 \mathrm{~cm}$ while the range of schoolbag weight are from $3 \mathrm{~kg}$ to $4.6 \mathrm{~kg}$. The mean weight for the students is $29.3 \mathrm{~kg}$ and the mean height is $125.9 \mathrm{~cm}$ while the mean weight of the schoolbag is 3.7 $\mathrm{kg}$. The interview results regarding the occurrence of discomfort experienced by the male students age 7 is as shown in the Figure 3. The results shows that 7 year old male student from this school do experience neck and back pain especially they experience distress on the lower back part of their body. Meanwhile, the average weight of the schoolbag shows that it is $12.6 \%$ which is more than $10 \%$ of the student's weight.

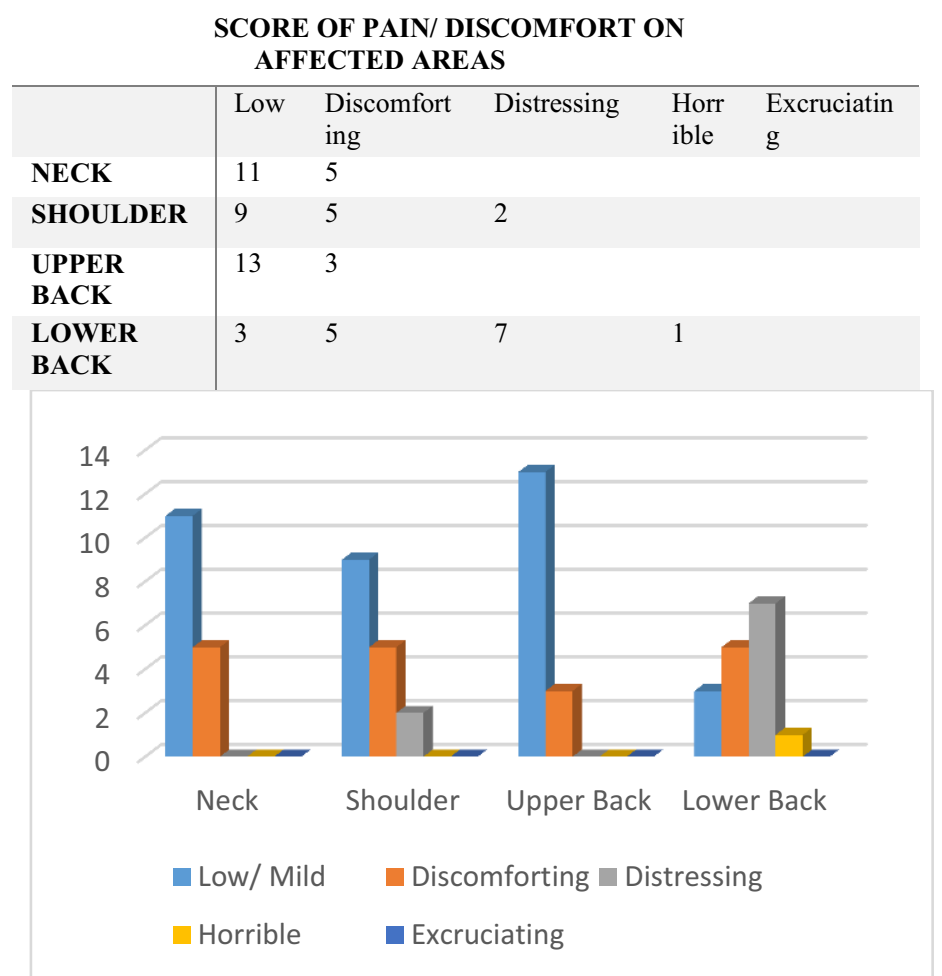

Figure 3. Results of discomfort level experience by male student age 7 .

\subsubsection{7 year old female student}

There are 14 respondents from this group where the range of weight are from $21.5 \mathrm{~kg}$ to $34.7 \mathrm{~kg}$ and the range of height are from $117 \mathrm{~cm}$ to $130 \mathrm{~cm}$ while the range of schoolbag weight are from $3.1 \mathrm{~kg}$ to $3.8 \mathrm{~kg}$. The mean weight is $27.3 \mathrm{~kg}$ and the mean height is $123.9 \mathrm{~cm}$ while the mean weight of schoolbag is $3.5 \mathrm{~kg}$. Meanwhile, the results of the interview among the 7 year old female students from this school regarding the occurrence of discomfort experience while carrying the schoolbag are as shown in Figure 4. From the result obtain, it shows that most of the students felt discomfort on the neck and the lower back area. Furthermore, the mean weight of the schoolbag for this group is $12.8 \%$ of their weight which shows that the heavy schoolbag has also taken toll on 7 year old female students. 
SCORE OF PAIN/ DISCOMFORT ON

AFFECTED AREAS

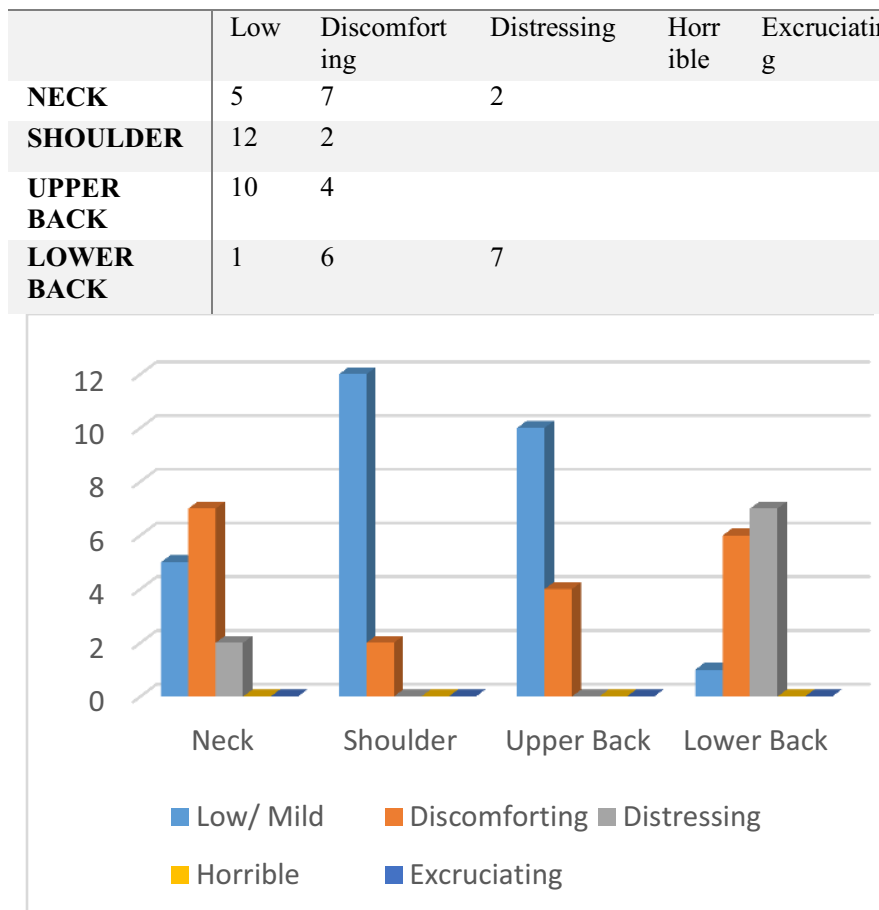

Figure 4. Results of discomfort level experience by female student age 7 .

\subsubsection{8 year old male student}

There are 14 respondents from this group where the range of weight are from $26.4 \mathrm{~kg}$ to $42.2 \mathrm{~kg}$ and the range of height are from $120 \mathrm{~cm}$ to $137 \mathrm{~cm}$ while the range of schoolbag weight are from $3.8 \mathrm{~kg}$ to $4.6 \mathrm{~kg}$. The mean weight is $34.5 \mathrm{~kg}$ and the mean height is $129.8 \mathrm{~cm}$ while the mean weight of schoolbag is $4.3 \mathrm{~kg}$. Based on the result shown in Figure 5, half of the student felt discomfort on their lower back area and some of them felt discomfort on their shoulder. Furthermore, their mean schoolbag weight is $12.5 \%$ of their mean weight. Neck and back pain does exists due to heavy schoolbags but the shoulder pain might be caused the strain of neck pain extending to the shoulders.

\section{SCORE OF PAIN/ DISCOMFORT ON} AFFECTED AREAS

\begin{tabular}{l|lllll}
\multicolumn{5}{c}{ AFFECTED AREAS } \\
& Low & $\begin{array}{l}\text { Discomfort } \\
\text { ing }\end{array}$ & Distressing & $\begin{array}{l}\text { Horr } \\
\text { ible }\end{array}$ & $\begin{array}{l}\text { Excruciatin } \\
\text { NECK }\end{array}$ \\
$\begin{array}{l}\text { SHOULDER } \\
\text { SHOU }\end{array}$ & 8 & 6 & & \\
UPPER & 11 & 3 & & \\
BACK & & & & \\
LOWER & 5 & 2 & 7 & \\
BACK & & & &
\end{tabular}

15

10

0

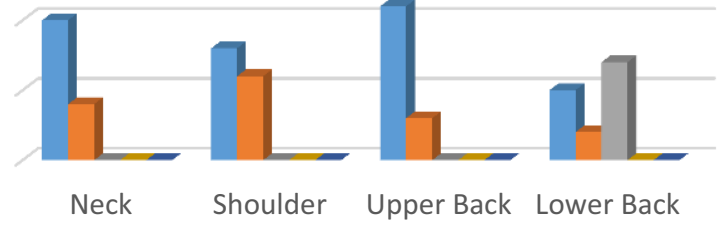

$\square$ Low/ Mild $\quad$ Discomforting $\square$ Distressing
Horrible $\quad$ Excruciating

Figure 5. Results of discomfort level experience by male student age 8 .

\subsubsection{8 year old female student}

There are 16 respondents from this group where the range of weight were from $21.7 \mathrm{~kg}$ to $37.1 \mathrm{~kg}$ and the range of height were from $119 \mathrm{~cm}$ to $133 \mathrm{~cm}$. The range of schoolbag weight was from $4.1 \mathrm{~kg}$ to $4.6 \mathrm{~kg}$. The mean weight is $30.2 \mathrm{~kg}$ and the mean height is $126.8 \mathrm{~cm}$. The mean weight of schoolbag is $4.3 \mathrm{~kg}$. According to the result obtained based on Figure 6, 8 year old most of the female students from this school experience distress pain on their lower back while carrying their schoolbag. On the other hand, the mean weight of schoolbag is $14.2 \%$ of the mean body weight for this group which is at least $1.4 \%$ more than all the other groups before. 


\begin{tabular}{|c|c|c|c|c|c|}
\hline \multicolumn{6}{|c|}{$\begin{array}{l}\text { SCORE OF PAIN/ DISCOMFORT ON } \\
\text { AFFECTED AREAS }\end{array}$} \\
\hline & Low & $\begin{array}{l}\text { Discomfort } \\
\text { ing }\end{array}$ & Distressing & $\begin{array}{l}\text { Horr } \\
\text { ible }\end{array}$ & $\begin{array}{l}\text { Excruciatin } \\
\mathrm{g}\end{array}$ \\
\hline NECK & 5 & 6 & 5 & & \\
\hline SHOULDER & 9 & 7 & & & \\
\hline $\begin{array}{l}\text { UPPER } \\
\text { BACK }\end{array}$ & 12 & 4 & & & \\
\hline $\begin{array}{l}\text { LOWER } \\
\text { BACK }\end{array}$ & 1 & 3 & 9 & 3 & \\
\hline 15 & & & & & \\
\hline 10 & & & & & \\
\hline & eck & Shoulder & Upper Back & Lowe & Back \\
\hline & w/ Mild & Discor & nforting $\square$ Dis & tressin & \\
\hline & orrible & Excruc & iating & & \\
\hline
\end{tabular}

Figure 6. Results of discomfort level experience by female student age 8 .

\subsubsection{9 year old male student}

There are 13 respondents for this group where the range of weight are from $32.1 \mathrm{~kg}$ to $50 \mathrm{~kg}$ and the range of height are from $133 \mathrm{~cm}$ to $142 \mathrm{~cm}$ while the range of schoolbag weight are from $4.8 \mathrm{~kg}$ to $5.6 \mathrm{~kg}$. The mean weight is $42.7 \mathrm{~kg}$ and the mean height is $137.8 \mathrm{~cm}$ while the mean weight of the schoolbag is $5.2 \mathrm{~kg}$. The results shown in Figure 7 indicates that, most of them felt discomfort and distress pain on the lower back of their body. The mean schoolbag weight for this group is $12.2 \%$ of the mean body weight of this group which is clearly more than $10 \%$ of their BW.
SCORE OF PAIN/ DISCOMFORT ON AFFECTED AREAS

\begin{tabular}{|c|c|c|c|c|c|}
\hline \multicolumn{6}{|c|}{$\begin{array}{l}\text { SCORE OF PAIN/ DISCOMFORT ON } \\
\text { AFFECTED AREAS }\end{array}$} \\
\hline & Low & $\begin{array}{l}\text { Discomfort } \\
\text { ing }\end{array}$ & Distressing & $\begin{array}{l}\text { Horr } \\
\text { ible }\end{array}$ & $\begin{array}{l}\text { Excruciatin } \\
\mathrm{g}\end{array}$ \\
\hline NECK & 7 & 5 & 1 & & \\
\hline SHOULDER & 11 & 1 & 1 & & \\
\hline $\begin{array}{l}\text { UPPER } \\
\text { BACK }\end{array}$ & 10 & 3 & & & \\
\hline $\begin{array}{l}\text { LOWER } \\
\text { BACK }\end{array}$ & 2 & 5 & 5 & 1 & \\
\hline
\end{tabular}

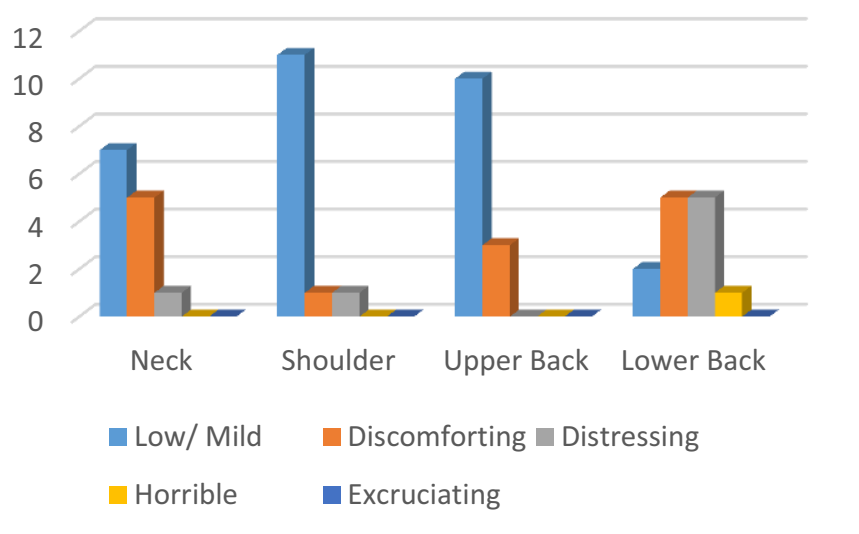

Figure 7. Results of discomfort level experience by male student age 9.

\subsubsection{9 year old female student}

There are 17 respondents for this group where the range of weight are from $21.7 \mathrm{~kg}$ to $47.9 \mathrm{~kg}$ and the range of height are from $120 \mathrm{~cm}$ to $142 \mathrm{~cm}$ while the range of schoolbag weight are from $4.8 \mathrm{~kg}$ to $5.3 \mathrm{~kg}$. The mean weight is $42.7 \mathrm{~kg}$ and the mean height is $137.8 \mathrm{~cm}$ while the mean weight of schoolbag is $5.2 \mathrm{~kg}$. According to the results from Figure 8, it shows that nearly half of the students experience a distress pain on their lower back due to carrying the schoolbag and at least 4 of them experience discomfort pain on their neck, shoulder, lower back and upper back while carrying the schoolbag. The mean schoolbag weight is also $12.2 \%$ of their mean body weight which the occurrence of prevalence of back and neck pain can be seen based on the result. 


\begin{tabular}{|c|c|c|c|c|c|}
\hline \multicolumn{6}{|c|}{$\begin{array}{l}\text { SCORE OF PAIN/ DISCOMFORT ON } \\
\text { AFFECTED AREAS }\end{array}$} \\
\hline & Low & $\begin{array}{l}\text { Discomfort } \\
\text { ing }\end{array}$ & Distressing & $\begin{array}{l}\text { Horr } \\
\text { ible }\end{array}$ & $\begin{array}{l}\text { Excruciatin } \\
\mathrm{g}\end{array}$ \\
\hline NECK & 13 & 4 & & & \\
\hline SHOULDER & 9 & 6 & 2 & & \\
\hline $\begin{array}{l}\text { UPPER } \\
\text { BACK }\end{array}$ & 11 & 6 & & & \\
\hline $\begin{array}{l}\text { LOWER } \\
\text { BACK }\end{array}$ & 1 & 4 & 8 & 4 & \\
\hline
\end{tabular}

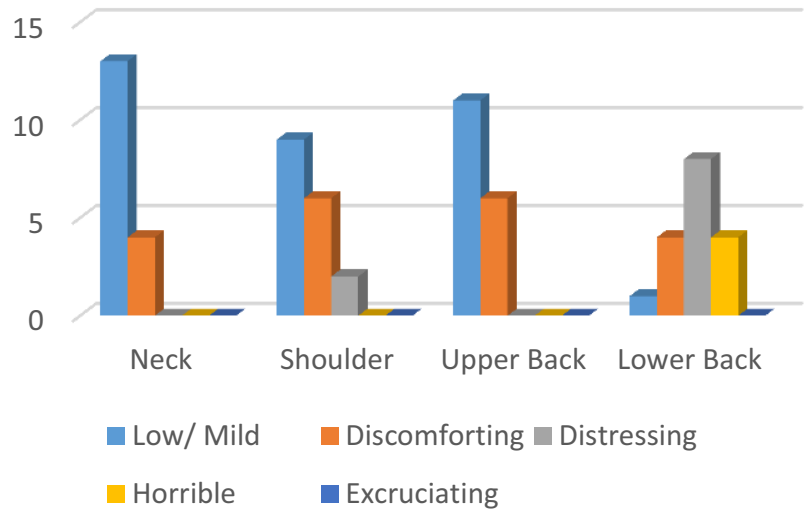

Figure 8. Results of discomfort level experience by male student age 9.

\subsection{Discussion}

According to the results and statistical analysis shown above, it is found that the prevalence of neck and back pain does exist among 7-9 year old school students and almost all students of all age and gender groups are affected. Comparing the results obtained above, it is found that most student age 7-9 of both gender felt distressing amount of discomfort especially on their lower back while most of them felt slight discomfort on other parts of thair body such as on neck, shoulder and upper back

Moreover, results obtained from this study shows that most of the student are carrying schoolbags that weighs around $12 \%$ to $14 \%$ more than their body weight. This means that the students carries $2 \%-4 \%$ more than the recommended weight. This excessive weight of the schoolbags will create an imbalanced stance and will cause the students to lean forward which in time will disrupts both coordination and posture of the students and worst, it may distort the back's natural curves. Furthermore, heavy backpacks creates a forward trunk lean which causes a forward head posture with an extended neck, creating neck and shoulder pain and making it difficult for muscles and ligaments to hold up the body. This could eventually lead to chronic muscle imbalance. There could also be other external factors such as schoolbag design and schoolbag carrying postures which can alter the results yet the weight of the schoolbag would still be the main factor of the prevalence of neck and back pain among 7-9 year old students.

Additionally, it is found quite common among the primary school students to use a trolley bag since looks like it is easier for children to transport their belongings but overlooked the fact that most schools in Malaysia have classrooms which are located on an at least a 3 story high building with no elevator and only a staircase to excess from one floor to another. Therefore, students who used trolley bags are unable to pull their bags once they have reached the staircase. The students will then carry their bags from there on. What would make it worst is that, the weight of the trolley bag itself without any load or baggage inside is at least $1 \mathrm{~kg}$ where this will further add up to the weight of the students belonging.

For future research, the amount of respondent for this study can be increased where this will improve the finding. The larger the number of respondent for the study, means more accurate data can be obtained and a clearer pattern of data can be acquired. Moreover, a comparative study could also be done to examine the effect of MSDs among students who carry their schoolbag in a proper posture with less loads on their schoolbags. This different grouping of research could help in determining a better posture of carrying schoolbag, ideal load that could be carried by a 7-9 year old student and improving the design of schoolbags in order to reduce MSDs among the school children.

\section{Conclusion}

In conclusion, this study showed the prevalence of neck, shoulder and back pain among 7-9 year old school students due to carrying heavy schoolbags. The weight of the schoolbags for each respective student is around $12 \%$ - $14 \%$ of the student's body weight. In addition, the analysis on the students height and weight and the weight of their schoolbag is used to assist in detecting the discomfort experienced among the students while carrying their schoolbag. Even though there are many factors exist contributing towards the prevalence of neck and back pain among 7-9 year old students such as the way of carrying the schoolbag or even the duration spent on carrying the schoolbag, but the main factor that contributes to this problem is overweight schoolbags will eventually leads on into many other small factors which later might leads to Musculoskeletal diseases in the future. It is hoped that the results from this study will help in suggesting and supporting improvements to be taken regarding this heavy schoolbag issue.

\section{References}

1. S. T. Wei, School Bags In Malaysia - A 'Heavy' Issue (Malaysian Digest, 2014)

2. R. Lim, A Load Too Heavy (The Star, 2013)

3. H. N. Shasmin, N. A. Abu Osman, R. Razali, J. Usman and W. A. B. Wan Abas, A Preliminary Study of Acceptable Load Carriage for Primary School Children (Biomed 06, IFMBE 2006)

4. Physical Work Demands in the Construction Industry (Dutch Labour Inspectorate, 2012)

5. Work practices guide for manual lifting, (National Institute of Occupational Safety and Health, 1981) 
6. J. Whittfield, S. J. Legg, and D. I. Hedderley, Schoolbag weight and musculoskeletal symptoms in New Zealand secondary schools. Appl. Ergono. 36, 193 (2005)

7. NBPA Schoolbag Survey '97 (National Back Pain Association, 1997)

8. D. D. Pascoe, D. E. Pascoe, Y.T. Wang, D. M. Shim, C.K. Kim. Influence of carrying book bags on gait cycle and posture of youths. Ergonomics. 40, 631 (1997)

9. S. Dockrell, S. Ciaran, C. Blake. Schoolbag carriage and schoolbag-related musculoskeletal discomfort among primary school children. Appl. Ergon. 51, 281 (2015)

10. T.M. Cook, D.A. Neumann, The effects of load placement on the EMG activity of the low back muscles during load carrying by men and women. Ergonomics. 30, 1413 (1987)

11. S. J. Legg, T. Ramsey, D. J. Knowles, The metabolic cost of backpack and shoulder load carriage. Ergonomics 35, 1063 (1992)

12. A. A James, M. R. Jafri, M. Abdul Rani, Back pain arising from schoolbag usage among primary schoolchildren. Int. J. Ind. Ergonom 44, 590 (2014)

13. D. Iman, N. Sorkhi, A. Pourhossein, A. Alipour, M. Asghari-Jafarabadi, Neck, shoulder and low back pain in secondary schoolchildren in relation to schoolbag carriage: should the recommended weight limits be gender-specific?. Appl. Ergon. 45, 437 (2014) 